\title{
Clear otorrhea: a case of Munchausen syndrome in a pediatric patient
}

\author{
Süay Özmen · Ömer Afșin Özmen · Taner Yılmaz
}

Received: 20 September 2006 / Accepted: 30 October 2007 / Published online: 21 November 2007

(C) Springer-Verlag 2007

\begin{abstract}
This paper reports a case of Munchausen syndrome in a pediatric patient. An 11-year-old girl presented with the complaint of clear fluid otorrhea. She underwent numerous investigations with deception of the physicians. The literature with respect to Munchausen syndrome in the pediatric patient is reviewed. Diagnosis of Munchausen syndrome is difficult especially during the initial assessment, although suspicion might be aroused by inconsistencies in the patient's history and discrepancies between signs and symptoms.
\end{abstract}

Keywords Otorrhea $\cdot$ Munchausen syndrome

\section{Introduction}

Feigned illness with the goal of receiving medical treatment for its own sake is known as Munchausen's syndrome. The syndrome is named after Baron Hieronymous Karl Friedrich von Munchausen (1720-1791) by Asher in 1951 [1]. Munchausen's syndrome is characterized by a self-inflicted lesion or as a legitimate disease. These patients have dramatic, but non-existent symptoms and demand radical treatment. The case represents an example of Munchausen syndrome in a pediatric patient.

\footnotetext{
S. Özmen $(\varangle) \cdot$ Ö. A. Özmen · T. Yılmaz

Department of Otorhinolaryngology Head and Neck Surgery,

Hacettepe University Medicine Faculty,

Sihhiye, Ankara, Turkey

e-mail: suayozturk@yahoo.com
}

\section{Case report}

An 11 year-old girl presented to a peripheral otolaryngology clinic with a 3 month history of clear discharge from her right ear. The discharge was odorless, occasionally containing bubbles, unrelated to her activities and meals. She had no history of trauma, ear surgery, ear infection, meningitis, parotid gland infection or pain. The discharge occured everyday, in an amount of 5-6 cc. She was hospitalized in another clinic for 15 days. In this period no evidence of discharge was observed. Clinical examination was normal. Computerized tomogram of the temporal bones, technetium scan of parotid glands, sialographic imagings were normal. With these findings she was referred to our center for further opinion. Her physical examination and audiologic tests were completely normal. We repeated the computed tomography with milimetric slides to rule out cerebrospinal fluid (CSF) and salivary fistula. It did not reveal any apparent fracture line or any abnormal communication; however, opacification of the right parotid gland and Stensen duct due to lipiodol sialography was demonstrated. She was living with her distant relatives and her parents were in her home city. Her father was schizophrenic and her mother was paraplegic. The patient's relatives brought 3-4 tubes filled with 3-4 cc of a clear fluid discharge. Analysis of this fluid was negative for $\beta-2$ transferrin, a biochemical marker of perilymphatic or CSF leakage. Amylase level was 12 (30-250). We decided to hospitalize her to observe closely. A plastic bag was applied to her right ear. The following day, she attempted to escape and confessed that she was filling water with spit in it to her right ear canal. At this point the patient's past medical and family history was carefully reviewed. It revealed that the patient had taken a depression therapy. It seemed to be impossible that an 11-year-old 
child would have the medical sophistication to simulate CSF or salivary fistula. We wondered if the patient's relatives had either been assisting the patient or were aware of her behavior which was refused by them. The suspicion of their involvement was never proven. The patient was referred to psychiatric consultation.

\section{Discussion}

Munchausen's syndrome is a disorder characterized by a triad of features: simulated illness, pathological lying and wandering hospital to hospital. The patient might simulate symptoms, aggravate a pre-existing illness or even selfinduce disease. Munchausen's syndrome must be differentiated from the other factitious disorders. In contrast to those with the conversion disorder, patients with Munchausen's syndrome voluntarily induce factitious symptoms as well as physical findings. Unlike malingerers, patients with Munchausen's syndrome have no apparent secondary gain beyond the medical procedure itself. These patients calmly submit to even painful medical procedures. Motives for adopting the sick role are often unclear, with the patients themselves at a loss to explain their actions. A review of their family and personal background might reveal a history of childhood split up, emotional neglect or abuse. Recent life experiences could also be important, with factitious behavior allowing an escape from the reality of their current situation. In the present case, the attitude of the patient was attributed to a subconcious desire to escape from her problems by psychiatrists.

Only two cases of Munchausen syndrome have been reported in pediatric group. One of them was a 10-year-old boy with factitious passage of renal stones [2] and the other was a 13-year-old boy presented with the complaint of otalgia and simulation of CSF leak [3].

Another clinical entity that must be separated is Munchausen's syndrome by proxy (MSBP). It was first described by Meadow in 1977 [4]. It is a disorder in which the fictitious illness is invented by another person. In MSBP, the child's carer, usually the mother fabricates illness in the child, either by inducing physical signs of illness or by deliberately misleading the physician into believing the child is ill. The victims are usually aged less than 6 years. In the literature, numerous cases of parents fabricating or producing illnesses in children, often resulting in death were reported $[5,6]$.

The first goal of treatment is reduction of potentially harmful investigations and procedures, but a therapeutic approach should be adopted. Involvement of a psychiatrist with the offer of continuing support might be helpful. After diagnosis and confrontation the patient will show some improvement with a reduction in factitious behavior, even though they continue to deny their role in creation of the symptoms, and refuse psychiatric care.

\section{References}

1. Asher R (1951) Munchausen's syndrome. Lancet 1:339-341

2. Sneed RC, Bell RF (1976) The dauphin of Munchausen: factitious passage of renal stones in a child. Pediatrics 58:127-130

3. Gilbert RW, Pierse PM, Mitchell PD (1987) Crytic otalgia: a case of Munchausen syndrome in a pediatric patient. J Otolaryngol 16(4):231-233

4. Meadow R (1977) Munchausen's syndrome by proxy: the hinterland of child abuse. Lancet 2:343-345

5. Rosenberg D (1987) Web of deceit: a literature review of Munchausen syndrome by proxy. Child Abuse Negl 11:547-563

6. Zohar Y, Avidan G, Schvili Y, Laurian N (1987) Otolaryngologic cases of Munchausen's syndrome. Laryngoscope 97:201-203 